\title{
The behaviour of prestressed concrete sections near the maximum moment*
}

\author{
by L. la Grange, B.Ing., Ph.D.
}

Contribution by R. G. Smith, B.Sc., Ph.D.,

A.M.I.C.E., A.M.I.Struct.E.

(University of Aberdeen)

It may not be necessary (as Dr la Grange stipulates) to have special control mechanisms to control the application of load by hydraulic jacks once the maximum resistance moment of the beam has been reached. From tests on the flexural behaviour of reinforced concrete continuous beams started in 1961 at the University of Aberdeen, the complete moment-curvature relations at the failure sections measured over a 2 in. length were obtained without difficulty. The beams were continuous over three spans, the end spans being $2 \mathrm{ft} 3$ in. long and the centre span $6 \mathrm{ft}$. Two equal concentrated loads were applied symmetrically about the central $2 \mathrm{ft}$, which was thus the length of the region of constant bending moment, the beam being designed to ensure failure between these loads. Outside the region of constant bending moment, the beam was considerably strengthened by the addition of mild-steel reinforcement and in some places by an increase in cross-section. This ensured that the ultimate moment capacity of these parts of the beam was large in relation to the region of constant bending moment so that general failure could not occur until the concrete strains at the failure section were far advanced. The load on the hydraulic jacks was thus always increasing until general failure of the beam occurred as a mechanism.

For a concrete cube strength of $4,000 \mathrm{lb} / \mathrm{in}^{2}$, maximum concrete strains at the failure section of approximately $1 \%$ for under-reinforced beams and $1.7 \%$ for over-reinforced beams were measured on a 2 in. gauge length over a test period of $2 \mathrm{~h}$. It is hoped to publish the results of these tests in the near future.

In order to ensure that the local curvature at the failure section would be obtained, the complete length of the region of constant moment was covered with " Demec" gauge points and complete sets of readings were taken at each load increment. There appears to be little justification for making the test section " very short" as stated by the author, as such artificial conditions are unlikely to be met with in practice.

The contributor ${ }^{(1,2)}$ has also observed high concrete strains at the failure sections of statically determinate unbonded prestressed concrete beams. Unlike beams with bonded reinforcement, however, the higher failure strains in the concrete occurred with the smaller depths of the neutral axis. The influence of the factor

*Pages 15.to 20 of Magazine No. 43.

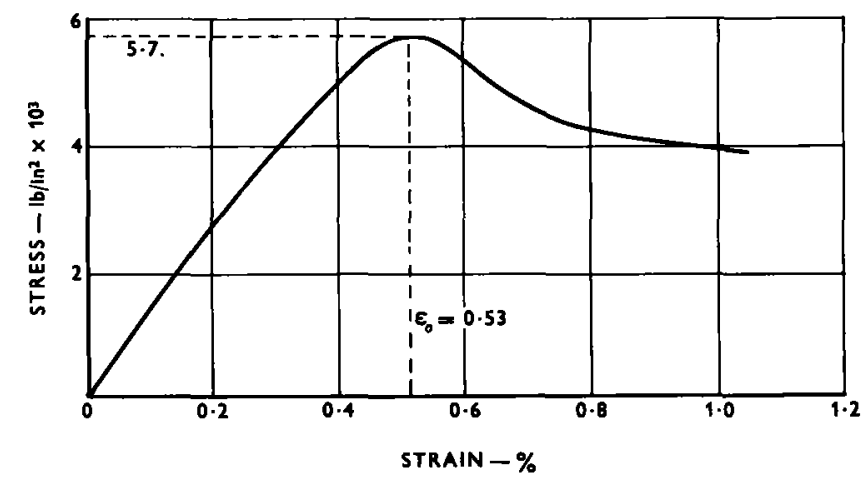

Figure I

$F^{(3)}$ is obviously important here. A stress-strain curve derived from one of the tests by a modification to the analysis of Prentis ${ }^{(1,4)}$ is shown in Figure I. The concrete cube strength was $7,360 \mathrm{lb} / \mathrm{in}^{2}$. It may be seen that $\varepsilon_{o}$ is approximately $0.53 \%$, but that the initial modulus of elasticity is much smaller than that obtained by Dr la Grange. The test lasted approximately $1 \mathrm{~h}$.

Dr la Grange is to be congratulated on his ingenious testing arrangement for determining the stress-strain relation of concrete in a uniform stress field. There is, however, a degree of approximation in the derivation of the curve which hardly warrants the statement that " the whole curve up to maximum stress could be obtained with great accuracy". In fact it would appear that the assumption is made that the concrete throughout the test specimen is homogeneous and isotropic so that, up to a stress just less than the maximum, the stress-strain curves in the various layers are identical. This is in direct contradiction to Figure 4 of the paper.

In my opinion, the direct application of stress-strain curves obtained from concentrically loaded prisms to the derivation of the stress-blocks in beams and hence to theoretical moment-curvature relations should be treated with the following reservations.

(1) The fact already referred to by Dr la Grange (and discussed in more detail by this contributor ${ }^{(2)}$ ) that the rates of straining of the various fibres in the compression zone of a beam are not constant.

(2) The effect of the strain gradient. In his hypothesis of the stress-strain behaviour of a concentrically loaded prism, Dr la Grange assumes layers of concrete at different strengths. This idealization may be taken one step further to the case of a prism eccentrically loaded so that the longitudinal strain distribution varies linearly from zero at one edge to a maximum at the other as shown in Figure II. The prism then 


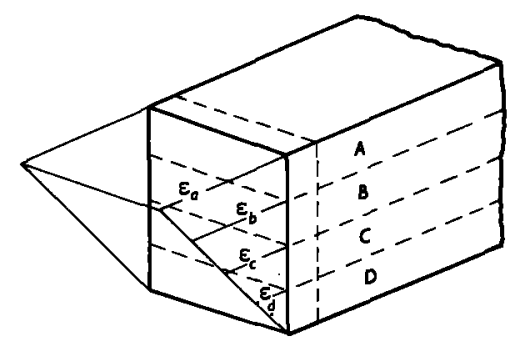

Figure II

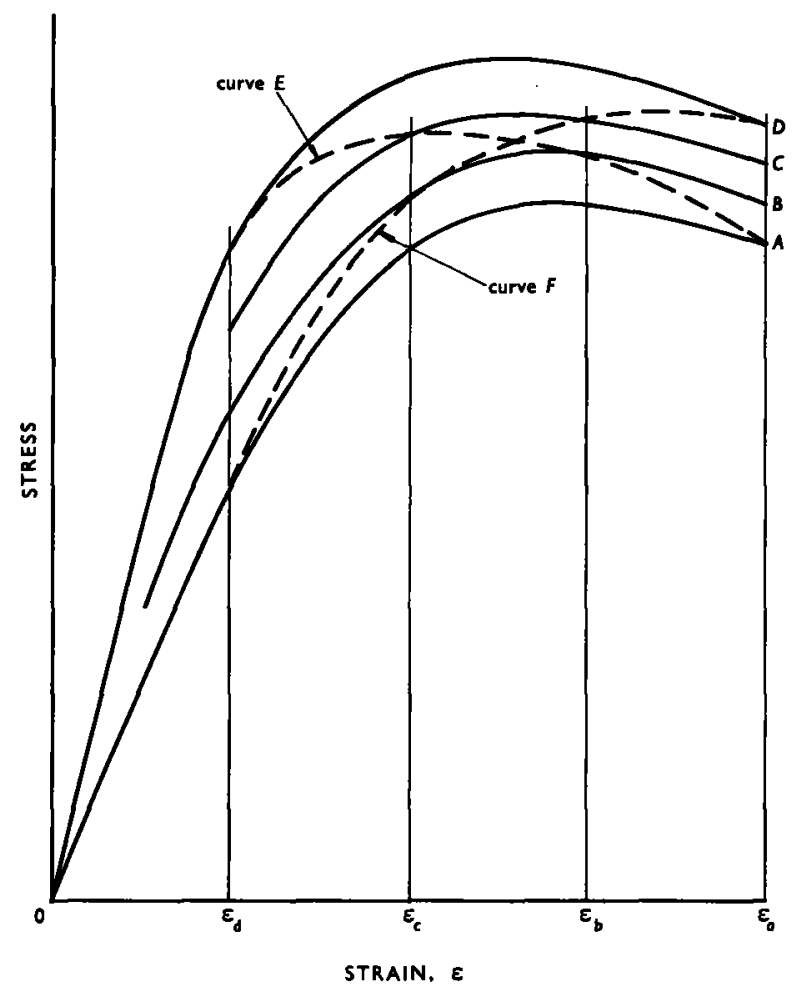

Figure III

simulates to some extent the compression zone of a beam above the neutral axis in a region of constant bending moment.

If the beam is cast in the normal way (with a trowelled top surface) it is well known that, owing to the effect of "water gain", the top layer of the beam may be weaker than the lower layers. It is thus plausible to assume that the concrete is arranged in horizontal layers with the probability that the strength increases with depth. The failure section of the prism would thus occur at the vertical slice where the concrete strengths are least. The prism is divided into four hypothetical horizontal layers of equal thickness $A$, $B, C$ and $D$ with corresponding strains, $\varepsilon_{a}, \varepsilon_{b}, \varepsilon_{c}$ and $\varepsilon_{d}$.

Figure III comprises the original Figure 4 with curve $n$ omitted, the curves $\mathrm{A}, \mathrm{B}, \mathrm{C}$ and $\mathrm{D}$ referring to the supposed strength of the layers. The shape of the stress-block acting on the cross-section must then be approximately as shown by curve $\mathrm{E}$. It is interesting to note that, in this case, $\varepsilon_{o}$ comes closer to the conventionally accepted value and that the curve is more parabolic in shape. If the beam had been cast upside down, the shape of the stress-block would be given by curve $F$.

Different shapes of stress-block would also be obtained if the neutral axis depth were smaller. For example, if the neutral axis coincided with the lower edge of layer $A$, the stress-block would be given by curve $A$. The actual shape of the stress-block is thus indeterminate, but it is probable that the maximum concrete strains will be of the same order as those found by Dr la Grange's prism tests.

I agree with Dr la Grange that for concrete strengths greater than $5,000 \mathrm{lb} / \mathrm{in}^{2}$, a parabolic stress-strain curve with a value of $\varepsilon_{o}$ of $0.5 \%$ is a reasonable approximation to the stress-strain relation at the failure section of a beam. The use of this curve, however, in a " rational " theory of flexural behaviour must be made in conjunction with a knowledge of the variation in the parameter $F$ (referred to previously) which may be considerably less than the currently accepted value of unity for well-bonded reinforcement. The estimation of the moment-curvature relation at adjacent sections is further complicated by the distribution of flexural cracks, the tensile strength of the concrete between the cracks and the bond conditions between the reinforcement and the concrete.

\section{REFERENCES}

1. SMITH, R. G. The ultimate load behaviour of unbonded prestressed concrete beams. Thesis presented to the University of Aberdeen for the degree of Ph.D. 1962.

2. SMITh, R. G. Discussion of paper by Rüsch. Researches toward a general flexural theory for structural concrete. Journal of the American Concrete Institute. Vol. 32, No. 9. March 1961. pp. 1160-1163.

3. BAKER, A. L. L. Recent researches in R.C. and its application to design. Journal of the Institution of Civil Engineers. Vol. 35, No. 4. February 1951.

4. PRENTIS, J. M. Analysis of inelastic bending stresses in concrete beams. Journal of the American Concrete Institute. Vol. 28, No. 3. September 1956. pp. 309-317.

\section{Reply by the author}

In the tests on three-span beams described by Dr Smith the " special control mechanisms to control the application of load "were incorporated-unintentionally perhaps. In these tests only a $2 \mathrm{ft}$ length of beam in the middle of the central span formed the " test specimen ". Everything outside the test section, i.e. the jacks, the supports and $4 \mathrm{ft} 3$ in. lengths of beam on each side of the test section, formed the "loading mechanism". By increasing the stiffness of the end spans the basic requirement for this type of test was met, i.e. the "loading mechanism" was stiffer 
than the "test specimen". The end span served the same purpose as the tension bar used in the compression tests described in the paper.

It is true that "very short " weak sections do not occur in practice. It is also true, however, that yielding always occurs over a very short length of the member, even within long lengths of constant strength and bending moment. The gauge length must therefore be short and, if only one gauge length is to be used, the yielding section must be pin-pointed by introducing a snort weak section. The method of covering a complete length of constant bending moment with a large number of short gauge lengths suffers from the disadvantage that the most critical gauge points, i.e. those near the yielding section, are often lost owing to spalling of the concrete surface. Perhaps Dr Smith developed a special technique for fixing gauge points which will be published with the results of his tests.

There can be little doubt that a variation in concrete strength with depth will affect the strength of the section as a whole. To allow for this in practice is hardly worth while because of the other uncertain factors in the analysis. In fact all these uncertain factors have very little effect on the calculation of the maximum moment of resistance-especially in underreinforced sections where yielding is controlled by the steel. It is only when the curvature at maximum moment is to be calculated that an accurate value of $\varepsilon_{o}$ becomes essential. In this respect it is gratifying to note that Dr Smith agrees that the value should be increased from the commonly accepted value of between 0.2 and $0.3 \%$ to approximately $0.5 \%$. 